J. Srinivasan, MBBS, $\mathrm{PhD}$

M.M. Ryan, MMed

D.M. Escolar, MD

B. Darras, MD

H.R. Jones, MD

Address correspondence and reprint requests to Dr. Jayashri Srinivasan, Department of Neurology, Lahey Clinic, 41 Mall Road, Burlington, MA 01805 jayashri_srinivasan@lahey.org

\section{Pediatric sciatic neuropathies}

\author{
A 30-year prospective study
}

\section{ABSTRACT}

Objective: The incidence, cause, and prognosis of sciatic neuropathy in children is not well understood. We report our 30-year experience of 53 patients with pediatric sciatic neuropathies (SN).

Methods: Prospective review of the history, physical examination, electrophysiologic findings, and clinical course of children with SN.

Results: The etiology of SN injury was varied and included trauma (13), iatrogenic causes (13) (8 orthopedic surgeries and 5 miscellaneous surgeries), prolonged extrinsic compression and immobilization (6), tumors (7), vascular (5), idiopathic and progressive (4), infantile and nonprogressive (2), and unknown, presumed postviral (3). Electrophysiologic studies demonstrated abnormalities in motor conduction studies of the peroneal nerve in 44/53 (83\%) or tibial nerve in 35/51 (67\%). Sensory conduction studies were abnormal in sural nerve in 34 of 43 cases $(79 \%)$, and superficial peroneal nerves in 15/25 (60\%). Needle EMG was abnormal in peroneal innervated muscles in all subjects, in tibial nerve innervated muscles in 43/51 (84\%), and in the hamstrings in 18/29 (62\%). Prognosis for recovery was variable and depended on the etiology and the severity of the nerve injury.

Conclusions: SN is an uncommon mononeuropathy in children. The causes of SN are varied in children compared to adults. Electrophysiologic studies in children may be limited by poor tolerance but play an important role in establishing the diagnosis. Neurology ${ }^{\circledR} 2011 ; 76: 976-980$

\section{GLOSSARY}

$\mathbf{A V M}=$ arteriovenous malformation; $\mathbf{N C S}$ = nerve conduction studies; $\mathbf{S N}=$ sciatic neuropathy

Mononeuropathies are uncommon in children; however, in our experience, pediatric sciatic neuropathy $(\mathrm{SN})$ represents approximately one-fourth of all mononeuropathies. ${ }^{1} \mathrm{SN}$ lesions may be underappreciated in childhood. We describe the clinical features of children who presented with SN over a 30-year period.

METHODS Patients. The cases reported were from the approximately 4,489 patients, ages $0-18$ years, seen at the EMG Laboratory, Children's Hospital Boston, between March 1979 and December 2009; and 612 subjects seen from 2003 to 2006 at the Children's Hospital at Westmead, Sydney, Australia.

Clinical assessment. Staff neurologists, neurosurgeons, or orthopedic surgeons evaluated all children in the study before EMG evaluation. A staff electromyographer reviewed the history and neurologic examination at the time of the EMG with the patient and parents/ guardians. Follow-up data were obtained by clinical examination, review of charts, telephone conversations, and occasionally a repeat EMG.

Electrophysiologic evaluation. Nerve conduction studies (NCS) and needle EMG were performed in children using Dantec Counterpoint (Dantec Electronic, Tonsbakken, Skovlunde, Denmark), TECS TE42 machine (Teca Corporation, Pleasantville, NY) or the Teca $^{\text {TM }}$ Synergy N-EM-EMG monitoring systems (Oxford Instruments, Oxford, UK); standard filter settings were utilized. Electrophysiologic studies were performed without sedation in the majority; in rare instances, sedation was used. In each child with a suspected SN, motor NCS included responses from the extensor digitorum brevis, abductor hallucis brevis, and in some instances tibialis anterior. Sensory NCS included sural nerve and in some instances superficial peroneal nerve responses. Plantar sensory responses were studied in preference to the technically difficult sural response in infants. Contralateral limbs were studied if there was possibility of a systemic process or multiple limb involvement. Normative data were as previously published. ${ }^{1} \mathrm{H}$-reflex studies and F-wave studies were performed infrequently. Muscles

From the Department of Neurology (J.S., H.R.J.), Children's Hospital Boston and Lahey Clinic, Burlington, MA; Children's Neuroscience Centre (M.M.R.), Royal Children's Hospital, Murdoch Children's Research Institute, Melbourne, Victoria, Australia; and Department of Neurology (D.M.E., B.D.), Children's Hospital Boston, Boston, MA.

Disclosure: Author disclosures are provided at the end of the article. 
in affected limb and ipsilateral paraspinal muscles were examined by needle EMG.

Standard protocol approvals, registrations, and patient consents. All patients or their guardians provided written informed consent to be treated at Boston's and Westmead's Children's Hospitals. Data pertaining to each patient were stored in a database approved by the Committee on Clinical Investigation at Boston Children's Hospital and Children's Hospital at Westmead, Australia, and reviewed for this study.

RESULTS These 53 patients constituted 1.2\% of the 4,489 studies performed during 1979-2009 at the Children's Hospital, Boston, and 612 Australian children seen between 2003 and 2006 at The Children's Hospital at Westmead. The age of the 53 patients ranged between 2 days and 18 years (table); 34 patients were male.

Etiology. The etiology of sciatic nerve injury was varied (table) and included trauma $(\mathrm{n}=13)$, iatrogenic causes $(n=13)$ including 8 orthopedic surgeries and 5 miscellaneous surgeries, prolonged extrinsic compression and immobilization (6), tumors (7), vascular (5), idiopathic and progressive (4), infantile and nonprogressive (2), and unknown, possible postviral (3).

Clinical data. Most children (51) presented with weakness, primarily tibialis anterior weakness (foot drop); 2 patients had only sensory symptoms without weakness. Weakness of plantar flexion was seen in 31 patients. Foot eversion $(n=21)$ and inversion $(\mathrm{n}=19)$ weakness was seen in fewer patients. Numbness below the knee was seen in all patients who were able to understand the meaning of this symptom. Pain as a symptom of SN was difficult to evaluate as the surgery or trauma that caused the SN was often associated with pain. In nontraumatic patients $(n=29)$, pain was seen in 8 patients. Palpable nerve hypertrophy was not documented in any patient. Prognosis was variable. Prognosis was generally good in the traumatic and iatrogenic $\mathrm{SN}$ especially if the nerve injury was identified early. SN due to vascular causes or due to tumor had a worse prognosis.

Electrophysiologic data. Electrophysiologic studies demonstrated abnormalities in motor studies of the peroneal nerve in $44 / 53(83 \%)$ or tibial nerve in 35/51 (67\%) children. Sensory studies were abnormal in sural nerve in 34/43 (79\%), and superficial peroneal nerves in 15/25 children (60\%). Needle EMG was abnormal in peroneal innervated muscles in all subjects, in tibial nerve innervated muscles in $43 / 51$ (84\%), and in the hamstrings in $18 / 29$ patients $(62 \%)$. EMG of other proximal muscles was performed infrequently because of poor patient tolerance of the procedure. To differentiate SN from peroneal neuropathies, children were only diagnosed with $\mathrm{SN}$ if they had abnormalities in conduction studies in nonperoneal nerves (tibial motor or sural sensory studies) or EMG abnormalities in tibialinnervated muscles or hamstrings.

DISCUSSION Mononeuropathies in children are rare, accounting for fewer than $10 \%$ of our referrals for EMG; this contrasts with adults, where they account for $30 \%$ of EMG referrals. ${ }^{1}$ In our series, direct trauma and iatrogenic mechanisms account for most $\mathrm{SN}$; tumor, vascular, and compression injuries are the next most common causes.

Traumatic SN was identified in 13 children and was associated with femoral fractures (4) and pelvis trauma including hip dislocation (3) and trauma and tibial fractures (2). Traumatic fractures and dislocations of the hip may be complicated by $\mathrm{SN}$ in up to $5 \%$ of children; mechanisms of nerve injury include laceration, stretching, and late entrapment in heterotopic calcification. ${ }^{2,3}$ The longer the delay in treatment of the dislocation, the greater the risk of sciatic nerve injury. ${ }^{4}$ One of our adolescents developed sciatic injury after closed reduction of a traumatic hip dislocation; EMG was consistent with a demyelinating lesion, and there was full recovery in 3 months. $\mathrm{SN}$ is a recognized complication of closed reduction. ${ }^{2}$ Other trauma that caused SN included penetrating wound to the gluteal region (2), injury from being swung around by the ankles in a 7-month-old (1), and earthquake crush injury (1). Following the earthquake in Bam, Iran, in 2003, sciatic injuries were common. ${ }^{5}$

Iatrogenic mechanisms were relatively common (13) and occurred after orthopedic interventions in 8 children. Hip surgeries associated with $\mathrm{SN}$ included surgery for slipped capital femoral epiphysis (2); this has been previously reported. ${ }^{6}$ Osteotomy to correct developmental dysplasia of hip resulted in SN (2); this is a known complication and continuous intraoperative EMG monitoring is recommended to reduce the risk of sciatic nerve injury. ${ }^{7}$ Hamstrings lengthening for cerebral palsy led to SN in 4 children; in one series of 292 children who underwent hamstring surgeries, 10\% developed postoperative nerve $\mathrm{SN} .{ }^{8}$ Other iatrogenic causes included surgery in lithotomy position in 2 patients. The pathogenesis of lithotomy-related $\mathrm{SN}$ is poorly understood; it is hypothesized that individuals with persistent fetal sciatic artery may be predisposed to $\mathrm{SN}$ in this position. ${ }^{9,10}$

Other iatrogenic causes included $\mathrm{SN}$ after serial casting for clubfoot (1); the mechanism of $\mathrm{SN}$ is unclear although some form of compression seems likely. IM injections, formerly a frequent cause of $\mathrm{SN}$, are now uncommon; only one case attributable to gluteal injection was identified in this series. ${ }^{11}$ One 


\section{Table Pediatric sciatic neuropathy: Etiologic classification}

\begin{tabular}{|c|c|c|}
\hline Cause (n) & $\begin{array}{l}\text { Age range } \\
\text { (mean age) }\end{array}$ & Details (n) \\
\hline \multirow[t]{9}{*}{ Trauma (13) } & 7 mo-17 y $(12.3$ y) & Femur fracture (2) \\
\hline & & Tibial fracture (1) \\
\hline & & MVA with pelvic, or femur or tibial fracture (4) \\
\hline & & MVA with hip dislocation (1) \\
\hline & & Fall with hip dislocation (1) \\
\hline & & Penetrating wound thigh (1) \\
\hline & & Knife wound buttock (1) \\
\hline & & Crush injury after earthquake (1) \\
\hline & & 7-month-old swung around by legs (1) \\
\hline \multirow[t]{3}{*}{ Orthopedic surgery ( 8 ) } & $8 y-15 y(12 y)$ & Cerebral palsy following leg lengthening (4) \\
\hline & & $\begin{array}{l}\text { Pelvic osteotomy and spica cast for } \\
\text { congenital hip dysplasia (2) }\end{array}$ \\
\hline & & Hip surgery for slipped femoral epiphysis (2) \\
\hline \multirow[t]{5}{*}{ Other surgeries (5) } & $3 \mathrm{mo}-14$ y $(7.5 \mathrm{y})$ & $\begin{array}{l}\text { Lithotomy position for repair of } \\
\text { hypospadiasis (1) }\end{array}$ \\
\hline & & Lithotomy position for ileo-anal pull through (1) \\
\hline & & Surgery to foot followed by limb casting (1) \\
\hline & & Intramuscular gluteal injection (1) \\
\hline & & Drainage of gluteal abscess (1) \\
\hline \multirow{6}{*}{$\begin{array}{l}\text { Prolonged compression } \\
\text { or immobilization (6) }\end{array}$} & $1 \mathrm{mo}-17$ y $(11.2$ y) & Phencyclidine overdose (1) \\
\hline & & $\begin{array}{l}\text { Transposition of great vessels with severe } \\
\text { pulmonary vascular obstruction, prolonged } \\
\text { squatting to alleviate dyspnea (1) }\end{array}$ \\
\hline & & $\begin{array}{l}\text { Complicated pressure sore over } \\
\text { buttock (1) }\end{array}$ \\
\hline & & $\begin{array}{l}\text { Aortic valve replacement with prolonged } \\
\text { intubation and ECMO support (1) }\end{array}$ \\
\hline & & Body cast for L3 compression fracture (1) \\
\hline & & Serial limb casting for clubfoot (1) \\
\hline \multirow[t]{6}{*}{ Tumor (7) } & 18 mo-16 y $(12$ y) & Femoral osteosarcoma (2) \\
\hline & & Rhabdomyosarcoma (1) \\
\hline & & Undifferentiated lymphoma (1) \\
\hline & & Neuroblastoma (1) \\
\hline & & Intraneural perineurioma (1) \\
\hline & & Plexiform neurofibroma (1) \\
\hline \multirow[t]{4}{*}{ Vascular (5) } & $4 y-14$ y $(7.4 y)$ & $\begin{array}{l}\text { Premature delivery at } 26 \text { weeks gestation } \\
\text { and umbilical artery catheterization (1) }\end{array}$ \\
\hline & & $\begin{array}{l}\text { Embolization of lower extremity arteriovenous } \\
\text { malformation ( } 2 \text { ) }\end{array}$ \\
\hline & & Meningococcemia (1) \\
\hline & & Hypersensitivity vasculitis (1) \\
\hline $\begin{array}{l}\text { Idiopathic and } \\
\text { progressive (4) }\end{array}$ & $6 y-17$ y $(11.3 y)$ & $\begin{array}{l}\text { Progressive weakness of sciatic innervated } \\
\text { muscles (4) }\end{array}$ \\
\hline Infantile (2) & $2 \mathrm{~d}-22 \mathrm{mo}(11 \mathrm{~m})$ & $\begin{array}{l}\text { Weakness of sciatic innervated muscles at } \\
\text { birth (2) }\end{array}$ \\
\hline $\begin{array}{l}\text { Unknown } \\
\text { (postviral?) (3) }\end{array}$ & $9 y-13$ y $(10.7)$ & $\begin{array}{l}\text { Unknown cause, preceded by mild viral } \\
\text { illness (3) }\end{array}$ \\
\hline
\end{tabular}

Abbreviations: $\mathrm{ECMO}=$ extracorporeal membrane oxygenation; $\mathrm{MVA}=$ motor vehicle accident.

patient developed SN immediately after drainage of a large gluteal abscess at the age of 3 months; it is possible that it was the abscess (not the drainage) that caused the SN. There are reports of gluteal abscesses, both septic and tuberculous, causing SN. ${ }^{12,13}$

Extrinsic compression occurred in 6 patients, 3 of whom were teenagers. One 17-year-old patient had bilateral SN following prolonged unconsciousness in supine position after an overdose of phencyclidine; this has been reported after heroin overdose ${ }^{14}$ and alcohol intoxication. ${ }^{15}$ One 14-year-old patient, a thin child, had transposition of the great vessels with pulmonary hypertension resulting in severe dyspnea; he was in a squatting position with his heels tucked under his buttocks for hours and developed SN. Another premature baby had a complicated antenatal period, followed by the development of a pressure sore over the buttock and ipsilateral SN; the etiology was probably compression. A 12 -year-old patient developed SN during a stormy postoperative course after aortic valve replacement, with prolonged intubation and extracorporeal membrane oxygenation. The etiology of his SN was not clear; it may have been due to compression or nerve infarct. SN has been described after intra-aortic balloon placement in adults. ${ }^{16}$ In 2 children, $\mathrm{SN}$ was seen following prolonged spica body casting for lumbar vertebral fracture secondary to leukemia and for clubfoot; this is probably due to compression of the nerve. $\mathrm{SN}$ has been reported in an adult after a spica body cast. ${ }^{17}$

SN due to tumor was seen in 7 patients; we have reported this. ${ }^{18}$ In 3 children, this was due to infiltration of the nerve by sarcomas external to the nerve, an osteosarcoma of the femur in 2 patients and a rhabdomyosarcoma of the pelvis in one child. The patient with rhabdomyosarcoma presented with findings suggestive of a perirectal abscess; however, persistent severe pain, abnormal enhancement on imaging studies, and subsequent development of SN led to the diagnosis of the sarcoma. This clinical scenario of rhabdomyosarcoma mimicking an abscess is recognized. ${ }^{19}$ Pain out of proportion to the size of the abscess and delay in healing should alert one to this rare but potentially fatal diagnosis. Tumor infiltration of the sciatic nerve by undifferentiated lymphoma was seen in a young boy who presented with severe lower limb pain; autopsy revealed sciatic nerve infiltration, a rare complication of lymphoma. ${ }^{20}$ An 18-month-old boy presented with slowly progressive SN due to a neuroblastoma of the pelvis. SN due to pelvic neuroblastoma has been reported ${ }^{21}$; it has also been seen following surgery for neuroblastoma. ${ }^{22}$ One 13-year-old boy presented with numbness and foot drop and was found to have enlargement of the $\mathrm{SN}$ on MRI; biopsy showed intraneural perineurioma, an extremely rare diagnosis. ${ }^{23}$ The nature of perineuriomas is not clearly understood; it is thought 
to be a neoplasm, although some believe that it is an inflammatory process. ${ }^{24}$ Giant hypertrophy or plexiform neurofibroma of the sciatic nerve was suspected in one boy based on MRI findings of a mildly enlarged, enhancing sciatic nerve, although biopsy was nondiagnostic. This patient had slowly progressive sciatic neuropathy that developed over 6 years; on follow-up, he remained stable, suggesting that if he had a tumor it was slow growing. Therefore, both benign and malignant tumors must be considered in any child presenting with a progressive sciatic mononeuropathy. Sciatic neurofibroma can be the primary manifestation of neurofibromatosis. ${ }^{25}$ Lymphomas, ${ }^{26}$ leukemia, ${ }^{27}$ or leiomyosarcomas ${ }^{28}$ may initially be diagnosed in children by their involvement of the sciatic nerve. As a rule, leg pain is the most common presentation of sciatic nerve tumors; weakness is usually not prominent early.

We found vascular causes for SN in 5 children; 4 of these cases were reported by us previously. ${ }^{29}$ One child had umbilical artery catheterization and following the procedure developed SN. The likely pathogenesis is thromboembolism of the inferior gluteal artery and ischemia of the sciatic nerve. There are rare reports of sciatic and peroneal neuropathies following umbilical artery catheterization. ${ }^{30}$ Two of our children, a 4-year-old with an arteriovenous malformation (AVM) of the right lower extremity and a 10-year-old with iliac artery stenosis and AVM, developed SN following embolization procedures; this is an infrequent complication of embolization. ${ }^{31}$ One 3-year-old boy with disseminated intravascular coagulation due to meningococcemia developed $\mathrm{SN}$ in one limb and an ischemic contralateral lower limb that required amputation; this is an unusual complication of meningococcemia. ${ }^{32}$ A teenager developed $\mathrm{SN}$ secondary to poststreptococcal vasculitis; this rare occurrence has been seen with $\beta$-hemolytic streptococcal infection. ${ }^{33}$

Idiopathic progressive $\mathrm{SN}$ was diagnosed in 4 boys presenting with slowly progressive sciatic distribution weakness. The mean age at presentation was 13 years and neuroimaging revealed normal sciatic nerves in all. In one child, a limited surgical exploration failed to demonstrate a site of potential entrapment. Electrophysiologic studies in idiopathic progressive mononeuropathies demonstrate a progressive axonal lesion without any diagnostic abnormalities on imaging studies or on surgical exploration. ${ }^{34}$ Rarely, idiopathic $\mathrm{SN}$ may be due to a constricting band and surgical release can result in improvement of symptoms. ${ }^{35}$

Infantile or congenital SN (table) was seen in 2 children, at ages ranging from 2 days to 22 months; SN was unilateral in one and bilateral in another. Prenatal compression of the sciatic nerve has been documented previously. ${ }^{36}$ Prenatal injuries are thought to be secondary to external compression from reduced fetal activity, especially when associated with decreased amniotic fluid, amniotic bands, or uterine abnormalities. ${ }^{36}$ In one series of 21 patients with neonatal SN, no cause was found in the majority; recovery was good in most patients. ${ }^{37}$

In 3 children, the etiology of SN could not be determined, but the onset appeared to follow a viral illness; this may have been coincidental. Postviral SN has been demonstrated after herpes zoster infection, although it is unclear if this represents a mononeuropathy or radiculopathy. ${ }^{38}$

$\mathrm{SN}$ is an uncommon mononeuropathy in children and the causes of $\mathrm{SN}$ are varied and unique. Traumatic and iatrogenic causes predominate in our series. Clinical examination usually reveals weakness of tibialis anterior in almost all patients and gastrocnemius weakness in the majority. It may be difficult to delineate sensory loss in young children. Electrophysiologic studies in children can be challenging and may be limited by the children's intolerance of the study. Abnormalities on EMG may be primarily seen in the common peroneal nerve division ${ }^{39}$; to make a definitive electrophysiologic diagnosis of $\mathrm{SN}$ in children we suggest that in addition to peroneal distribution findings, there should be abnormalities in conduction studies in nonperoneal nerves (tibial motor or sural sensory studies) or EMG abnormalities in tibial-innervated muscles and/or hamstrings. MRI will become increasingly useful as the higher resolution 3-T units are utilized. Prognosis for recovery is variable and appears to depend on the etiology and severity of the SN.

\section{DISCLOSURE}

Dr. Srinivasan reports no disclosures. Dr. Ryan serves as an Associate Editor of the Journal of Pediatric Neurology and on the editorial board of the Journal of Clinical Neuroscience and receives research support from PTC Therapeutics, Inc. Dr. Escolar has received funding for travel or speaker honoraria from Athena Diagnostics, Inc. and Acceleron Pharma; serves as a consultant for Gerson Lheman Group (GLC), Medacorp, and Acceleron Pharma; serves on the speakers' bureau of Athena Diagnostics, Inc.; and receives research support from the NIH, the Muscular Dystrophy Association, and the Foundation to Erradicate Duchenne (FED). Dr. Darras has received publishing royalties from UpToDate, Inc.; serves as a consultant for Genzyme, Inc.; receives research support from PTC Therapeutics, Inc., the NIH (NIAMS, NINDS), the SMA Foundation, the Muscular Dystrophy Association, the New England Research Institutes/ SMA Foundation, and the Slaney Family Fund for SMA; and has served as a consultant in medico-legal cases not related to SMA. Dr. Jones receives publishing royalties for Clinical Neurophysiology of Infants, Children and Adolescents (Butterworth Heinemann, 2005).

Received July 27, 2010. Accepted in final form November 23, 2010. 


\section{REFERENCES}

1. Jones HR, Gianturco L, Gross PT, Buchhalter J. Sciatic neuropathies in childhood: a report of ten cases and review of the literature. J Child Neurol 1988;3:193-199.

2. Cornwall R, Radomisli TE. Nerve injury in traumatic dislocation of the hip. Clin Orthop Relat Res 2000;377:84-91.

3. Holden CP, Holman J, Herman MJ. Pediatric pelvic fractures. J Am Acad Orthop Surg 2007;15:172-177.

4. Hillyard RF, Fox J. Sciatic nerve injuries associated with traumatic posterior hip dislocations. Am J Emerg Med 2003;21:545-548.

5. Ahrari MN, Zangiabadi N, Asadi A, Sarafi Nejad A. Prevalence and distribution of peripheral nerve injuries in victims of Bam earthquake. Electromyogr Clin Neurophysiol 2006;46:59-62.

6. Riley PM, Weiner DS, Gillespie R, Weiner SD. Hazards of internal fixation in the treatment of slipped capital femoral epiphysis. J Bone Joint Surg Am 1990;72:15001509.

7. Pring ME, Trousdale RT, Cabanela ME, Harper CM. Intraoperative electromyographic monitoring during periacetabular osteotomy. Clin Orthop Relat Res 2002;400: $158-164$.

8. Karol LA, Chambers C, Popejoy D, Birch JG. Nerve palsy after hamstring lengthening in patients with cerebral palsy. J Pediatr Orthop 2008;28:773-776.

9. Burkhart FL, Daly JW. Sciatic and peroneal nerve injury: a complication of vaginal operations. Obstet Gynecol 1966; 28:99-102.

10. Romfh JH, Currier RD. Sciatic neuropathy induced by the lithotomy position. Arch Neurol 1983;40:127.

11. Combes MA, Clark WK, Gregory CF, James JA. Sciatic nerve injury in infants: recognition and prevention of impairment resulting from intragluteal injections. JAMA 1960;173:1336-1339.

12. Shames JL, Fast A. Gluteal abscess causing sciatica in a patient with systemic lupus erythematosus. Arch Phys Med Rehabil 1989;70:410-411.

13. Baba H, Okumura Y, Furusawa N, et al. Dumb-bell shaped tuberculous abscess across the greater sciatic notch compressing both sciatic nerves. Spinal Cord 1998;36: $584-587$.

14. Gille M, Delbecq J, Depré A, van den Bergh P. Painful sciatic neuropathy after heroin overdose. J Neurol 1995 ; 242:478-480

15. Kornetzky L, Linden D, Berlit P. Bilateral sciatic nerve "Saturday night palsy." J Neurol 2001;248:425.

16. McManis PG. Sciatic nerve lesions during cardiac surgery. Neurology 1994;44:684-687.

17. Synek VM, Hardy AE. Triplicate post-traumatic sciatic nerve palsy: evoked potentials in the diagnosis. Clin Exp Neurol 1985;21:157-163.

18. McMillan HJ, Srinivasan J, Darras BT, et al. Pediatric sciatic neuropathy associated with neoplasms. Muscle Nerve 2011;43:183-188

19. Hill DA, Dehner LP, Gow KW, et al. Perianal rhabdomyosarcoma presenting as a perirectal abscess: a report of 11 cases. J Pediatr Surg 2002;37:576-581.

20. Misdraji J, Ino Y, Loius DN, et al. Primary lymphoma of peripheral nerve: report of four cases. Am J Surg Pathol 2000;24:1257-1265.
21. Nesbitt KA, Vidone RA. Primitive neuroectodermal tumor (neuroblastoma) arising in sciatic nerve of a child. Cancer 1976;37:1562-1570.

22. Cruccetti A, Kiely EM, Spitz L, et al. Pelvic neuroblastoma: low mortality and high morbidity. J Pediatr Surg 2000;35:724-728.

23. Thomas JE, Piepgras DG, Scheithauer BW, et al. Neurogenic tumors of the sciatic nerve: a clinicopathologic study of 35 cases. Mayo Clin Proc 1983;58:640-647.

24. Emory TS, Scheithauer BW, Hirose T, et al. Intraneural perineurioma: a clonal neoplasm associated with abnormalities of chromosome 22. Am J Clin Pathol 1995;103: 696-704.

25. Thomas JE, Piepgras DG, Scheithauer B, et al. Neurogenic tumors of the sciatic nerve: a clinicopathologic study of 35 cases. Mayo Clin Proc 1983;58:640-647.

26. Descamps MJ, Barrett L, Groves M, et al. Primary sciatic nerve lymphoma: a case report and review of the literature. J Neurol Neurosurg Psychiatry 2006;77: 1087-1089.

27. Stillman M, Christensen JW, Payne R, Foley KM. Leukemic relapse presenting as sciatic nerve involvement by chloroma (granulocytic sarcoma). Cancer 1988;62:20472050 .

28. Benyahya E, Etaouil N, Janani S, et al. Sciatica as the first manifestation of a leiomyosarcoma of the buttock. Rev Rhum Engl Ed 1997;64:135-137.

29. Srinivasan J, Escolar D, Ryan MM, Darras B, Jones HR. Pediatric sciatic neuropathies due to unusual vascular causes. J Child Neurol 2008;23:738-741

30. Fok TF, Ha MH, Leung KW, Wong W. Sciatic nerve palsy complicating umbilical arterial catheterization. Eur J Pediatr 1986;145:308-309.

31. Ney JP, Shih W, Landau ME. Sciatic neuropathy following endovascular treatment of a limb vascular malformation. J Brachial Plex Peripher Nerve Inj 2006;15:8.

32. Roig M, Santamaria J, Fernández E, Colomer J. Peripheral neuropathy in meningococcal septicemia. Eur Neurol 1985;24:310-313.

33. Traverso F, Martini F, Banchi L, et al. Vasculitic neuropathy associated with beta-haemolytic streptococcal infection: a case report. Ital J Neurol Sci 1997;18:105107.

34. Engstrom JW, Layzer RB, Olney RK, Edwards MB. Idiopathic, progressive mononeuropathy in young people. Arch Neurol 1993;50:20-23.

35. Venna N, Bielawski M, Spatz EM. Sciatic nerve entrapment in a child: case report. J Neurosurg 1991;75:652654 .

36. Sheth D, Gutmann L, Blumenthal DT, et al. Compressive sciatic neuropathy due to uterine abnormality. Muscle Nerve 1994; 17:1486-1488.

37. Ramos-Fernandez JM, Oliete-Garcia FM, RoldanAparicio S, et al. Neonatal sciatic palsy: etiology and outcome of 21 cases. Rev Neurol 1998;26:752-755.

38. Wendling D, Langlois S, Lohse A, et al. Herpes zoster sciatica with paresis preceding the skin lesions: three case reports. Joint Bone Spine 2004;71:588-591.

39. Yuen EC, So YT, Olney RK. The electrophysiologic features of sciatic neuropathy in 100 patients. Muscle Nerve $1995 ; 18: 414-420$. 